\title{
Retraction Note to: Investigation of Co-Doped ZnO Nanowires by X-ray Absorption Spectroscopy and $A b$ Initio Simulation
}

\author{
MANH HUNG CHU,${ }^{1,2}$ VAN DUY NGUYEN,${ }^{1}$ DUC HOA NGUYEN, ${ }^{1}$ \\ and VAN HIEU NGUYEN ${ }^{1}$ \\ 1.-International Training Institute for Materials Science, Hanoi University of Science and \\ Technology, No. 1 Dai Co Viet, Hanoi, Vietnam. 2.—e-mail: mhchu@itims.edu.vn
}

\section{Retraction Note to: Journal of ELECTRONIC}

MATERIALS, Vol. 46, No. 6, 2017

DOI: 10.1007/S11664-016-5264-0

The Publisher has retracted this article at the request of the Editor-in-Chief, following an investigation that revealed extensive duplication of previous publications, and premature inclusion of preliminary data supplied by collaborators without prior approval. 